The Geneva Papers on Risk and Insurance, 17 (No. 64, July 1992), 371-385

\title{
An Analysis of the Climate Change Issue
}

\author{
by J. L. Rasmussen*
}

\begin{abstract}
The issue of climate change is approached from the description of the "greenhouse effect" and its implications for the earth-atmosphere-ocean climate system. The paper briefly summarizes the historical data record and discusses the use of numerical models of the general circulation of the coupled atmosphere-ocean system for studying climate change. Based upon the results of the scientific assessment undertaken by the WMO/ UNEP sponsored Intergovernmental Panel on Climate Change, the paper synthesizes our current knowledge of the predicted warmer earth, summarizes our best understanding of the impact of this global climate change on selected regions, and discusses the possible impact on the frequency and strength of weather systems. The paper concludes with an outlook for future observational systems and research efforts needed to reduce the uncertainties in our understanding of climate change and its impacts.
\end{abstract}

\section{Introduction}

The title of this paper - an analysis of the climate change issue - has many facets ranging from the physical system of ocean-atmosphere-cryosphere-biosphere (it is an energy and chemical coupling of truly global proportions) to major implications for society and economies. I will concentrate on the physical climate system and try to take the discussion of climate change down to what we might expect in changes in day-to-day weather, frequencies of certain weather phenomena and other impacts such as sea-level changes.

One must realize that to effectively discuss the climate we naturally discuss the physical system in statistical terms. This is perhaps not a problem for this audience but I like to remind myself of the actuary who drowned in a stream that on the average was 3 centimeters deep!

As a meteorologist, and organizer of weather forecasting operations, I am constantly aware of extreme events and the requirement to predict these events with adequate skill

* Director, World Weather Watch Department, World Meteorological Organization, Geneva. Paper presented at the Fourth International Conference on Strategic Planning and Issues in Insurance in London, on October 28 to 30, 1991. 
and with enough lead-time for appropriate measures to be taken to reduce the risk of loss of life and property damage. A comparable requirement to predict the climate and climate change exists but because of its complexity, global nature, and very long time scale, the problem is many times more difficult than the local weather forecast - we have only scratched the surface of this prediction problem. A major research effort is underway throughout the world to address it; major technological advances in observing systems (especially satellite and oceanographic systems) and major developments in the numerical modelling of the climate system are expected; but, because this issue is a political one, we as meteorologists are experiencing an unusual visibility that we really haven't learned to deal with yet. I think we are beyond the "don't know squared" situation - that is a situation where we don't know what we don't know - and have progressed to identifying those things that we know with some certainty and we are developing research and observational strategies to fill the gaps in our knowledge.

First I will briefly review the so-called "greenhouse effect" which is the general basis for the arguments behind the climate change issue. I will then touch on the use of numerical models to try to demonstrate the response of the climate system to the greenhouse forcing, and finally, to outline what is presently understood about the change in the weather and ocean conditions that we might expect.

There is considerable controversy regarding the details of the physical picture and its expected evolution - to minimize the bias in my reporting I will base my discussion on the scientific assessment undertaken under the sponsorship of the World Meteorological Organization and the United Nations Environment Programme. This is commonly referred to as the "IPCC Report - IPCC an alphabetization of Intergovernmental Panel on $\underline{\text { Climate }}$ Change. ${ }^{1}$ What the organizations did was to bring together the best possible scientific minds and the widest possible political/governmental interests to try to arrive at an assessment that satisfied both. I think they met with considerable success.

\section{The physical climate systems}

I will be talking about the climate system - it is convenient to try to describe all of the elements of the system in a schematic design such as shown in Figure 1. This diagram and several that follow are from a lecture presented by Dr. John Zillman at the tenth session of the WMO Regional Association V. ${ }^{2}$ The complexity of the climate system is easy to see here. One might compare, by way of an example, that for weather forecasting purposes we can deal with essentially the atmosphere and its interface with the land and ocean only, and ignore the biosphere and simplify the other interactions greatly. On the climate scale, the global earth-atmosphere system is in radiative equilibrium - radiating back to space the same amount of energy as received from the sun. Given this global radiation balance, we can then investigate the closed system inside the box - this is where

\footnotetext{
${ }^{1}$ Intergovernmental panel on Climate Change, IPCC, 1990. Assessment of Global Climate Change, I. Scientific assessment of Climate Change, II. Impacts Assessment of Climate Change, III. Response strategies assessment of Climate Change. World Meteorological Organization / United Nations Environmental Programme.

${ }^{2}$ J.W. Zillman, W. K. Downey and M. J. Manton, 1989. Climate Change and its Possible Impacts in the Southwest Pacific Region, scientific lecture presented at the Tenth Session of the WMO Regional Association V, Singapore, 14 to 24 November 1989.
} 
the greenhouse effect plays its crucial role. The energy to drive the atmosphere/ocean system is radiation from the sun (the short-wave radiation). However, the atmosphere is largely transparent to the solar radiation which is absorbed by the solid earth and ocean and which subsequently heat the atmosphere radiatively (long-wave radiation) and through convection and the process of evaporation-condensation of water.

Figure 1:

A schematic representation of the components of the global climate system

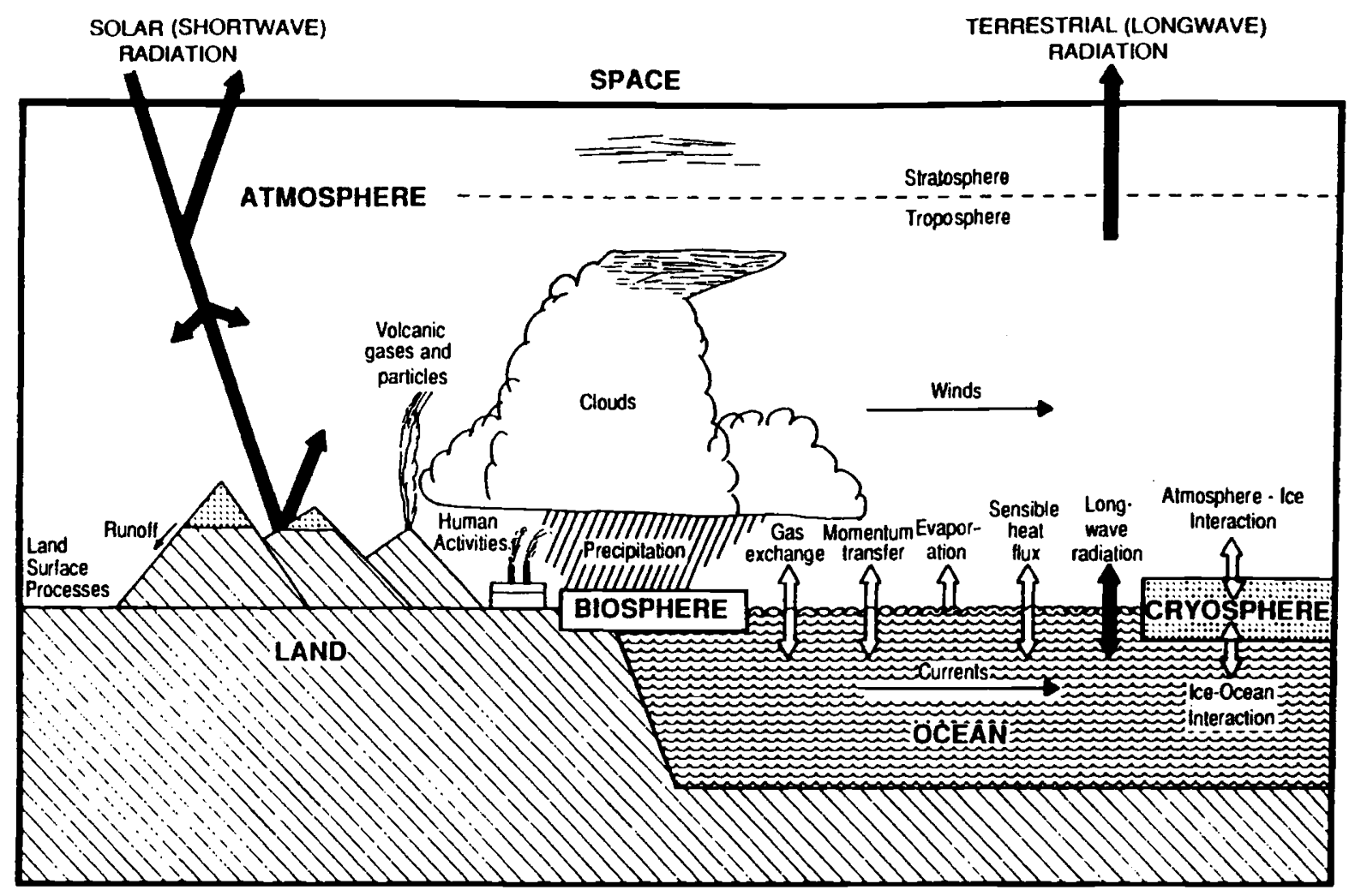

(Source: Zillman et al. 1989)

Figure 2 illustrates the way the greenhouse effect works by comparing what would happen without an atmosphere (left-hand side) and what happens with the atmosphere (right-hand side). The diagram is constructed like a plumbing system where the crosssection of the pipe is proportional to the global average energy flows for our present climate - the numbers are in watts per square meter. In the case with no atmosphere the planetary radiative temperature would be $255^{\circ} \mathrm{K}$ or $-18^{\circ} \mathrm{C}$. By contrast the case with the atmosphere gives a surface temperature of $+15^{\circ} \mathrm{C}$, some $33^{\circ}$ warmer. This is caused by the greenhouse effect. In the situation where there is more mass of efficient absorbers in the atmosphere (e. g. a higher fraction of greenhouse gases or more water vapour) 
then the loop of long-wave radiation will be enhanced and a temperature increase at the surface will be observed. An important component of the climate system is depicted here by the cloud symbol and the evaporation - condensation processes. As we will see this is at the heart of the major uncertainty in our knowledge at the present time.

Figure 2:

The greenhouse effect. In the absence of an atmosphere (left), the long-wave radiation emitted back to space will exactly equal the absorbed short-wave radiation (assuming an albedo of approximately 0.31) if the surface radiative temperature is $255 \mathrm{~K}$. With an atmosphere containing water vapour, carbon dioxide and other greenhouse gases (right) most of the upward radiation emitted from the surface is trapped and re-radiated downward and upward by cloud and greenhouse gases thus warming the earth's surface and cooling the upper layers of the atmosphere. The net long-wave radiative cooling of the atmospheric layer is offset by latent and sensible heat flux upward from the warmed surface. Radiativeconvective equilibrium is achieved when the globally averaged surface temperature reaches $289 \mathrm{~K}$. In the equilibrium situation, the atmospheric temperature falls off with height to temperatures well below the planetary temperature of $255 \mathrm{~K}$ as shown schematically above (centre). All heat fluxes are approximate global averages for the present climate and are given in Watts per square metre $\left(\mathrm{Wm}^{-1}\right)$

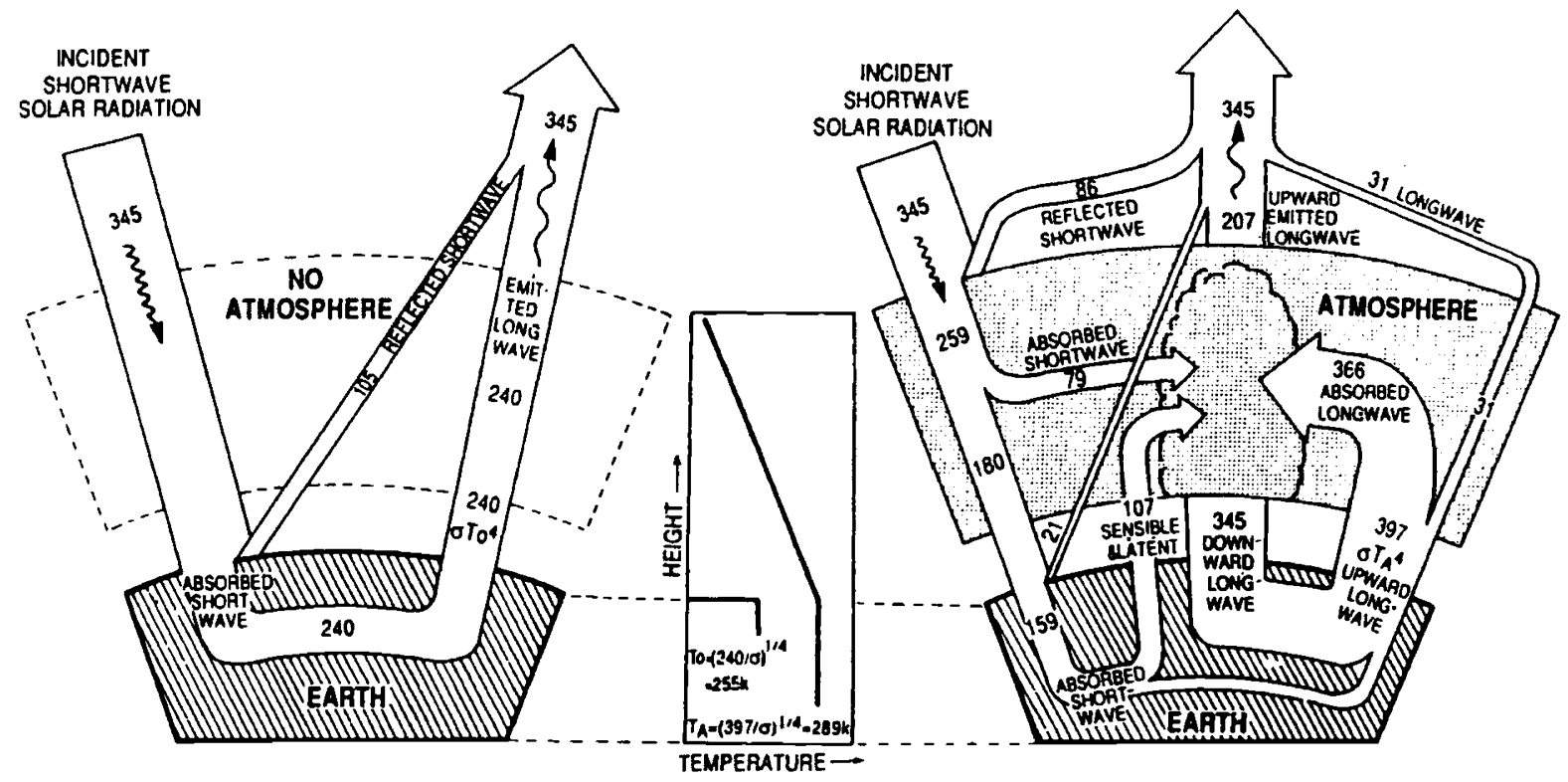

(Source: Zillman et. al. 1989)

A similar analysis of other planets illustrates the power of the "greenhouse effect" quite well and is shown in Figure 3. One sees here an example of a "super greenhouse" such as the atmosphere of Venus as well as a much lesser "greenhouse" such as on Mars. Our earth is in the middle range. So let us take a closer look at our climate system and list those constituents that play an important role in the greenhouse effect for the earth. 
Figure 3:

Greenhouse effect: evidence from other planets

\begin{tabular}{|l|c|c|c|c|c|}
\hline & $\begin{array}{c}\text { Surface } \\
\text { Pressure } \\
\text { (Relative } \\
\text { to Earth) }\end{array}$ & $\begin{array}{c}\text { Main } \\
\text { Greenhouse } \\
\text { Gases }\end{array}$ & $\begin{array}{c}\text { Surface } \\
\text { temperature } \\
\text { in absence of } \\
\text { Greenhouse } \\
\text { effect }\end{array}$ & $\begin{array}{c}\text { Observed } \\
\text { Surface } \\
\text { Temperature }\end{array}$ & $\begin{array}{c}\text { Warming } \\
\text { due to } \\
\text { Greenhouse } \\
\text { Effect }\end{array}$ \\
\hline VENUS & 90 & $>90 \% \mathrm{CO}_{2}$ & $-46^{\circ} \mathrm{C}$ & $477^{\circ} \mathrm{C}$ & $523^{\circ} \mathrm{C}$ \\
\hline EARTH & 1 & $\begin{array}{c}\sim 0.04 \% \mathrm{CO}_{2} \\
\sim 1 \% \mathrm{H}_{2} \mathrm{O}\end{array}$ & $-18^{\circ} \mathrm{C}$ & $15^{\circ} \mathrm{C}$ & $33^{\circ} \mathrm{C}$ \\
\hline MARS & 0.007 & $>80 \% \mathrm{CO}_{2}$ & $-57^{\circ} \mathrm{C}$ & $-47^{\circ} \mathrm{C}$ & $10^{\circ} \mathrm{C}$ \\
\hline
\end{tabular}

(Source: IPCC Report, 1990)

Figure 4 summarizes the major players. Here we see that while $\mathrm{CO}_{2}$ is the major "player", others such as chlorofluoro carbon (CFCs), methane and nitrous oxide all play a role, and a role that is increasingly important.

Figure 4:

Contributions from the greenhouse gases to change in climate forcing $1980-1990$

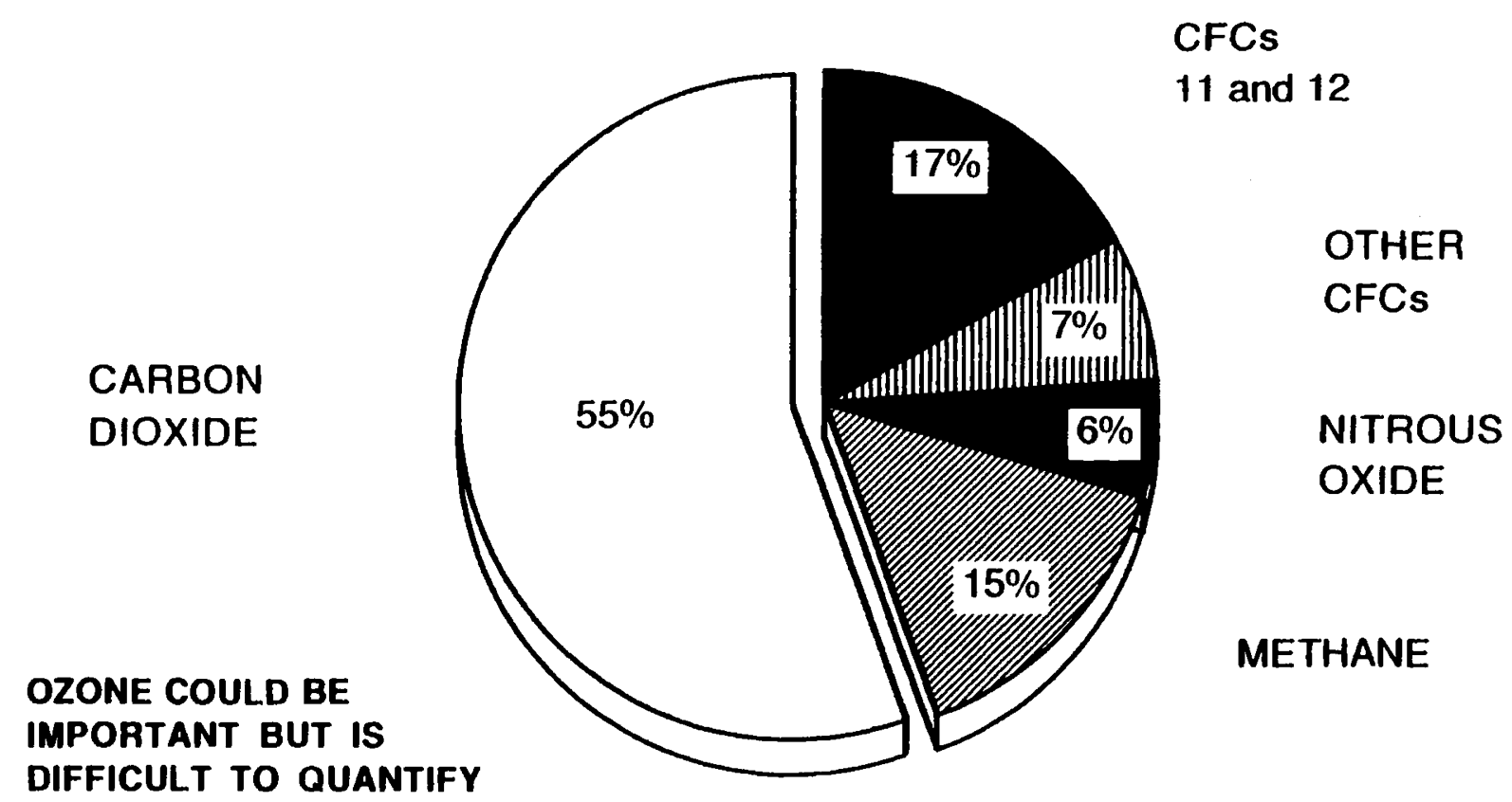

(Source: IPCC Report, 1990) 

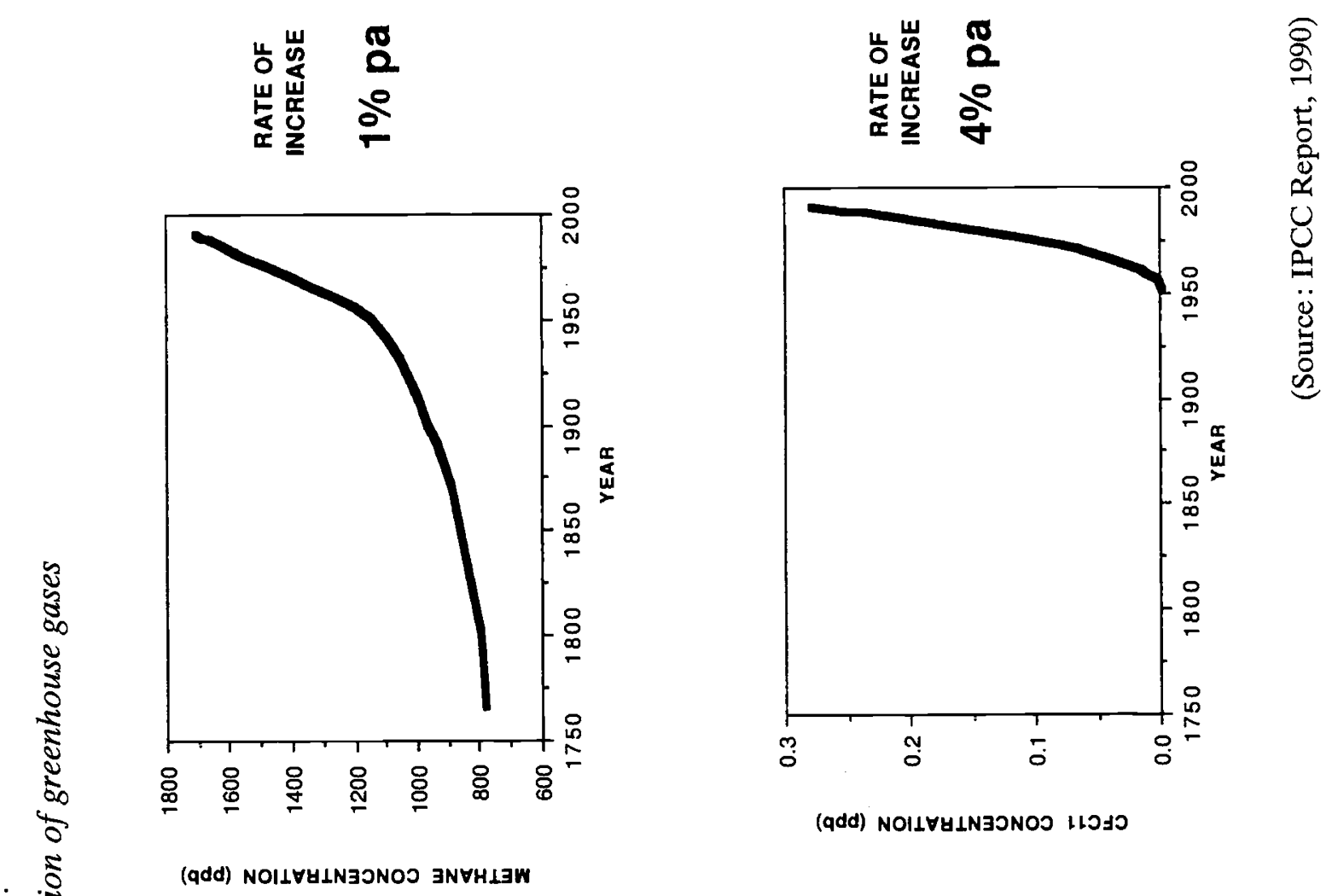

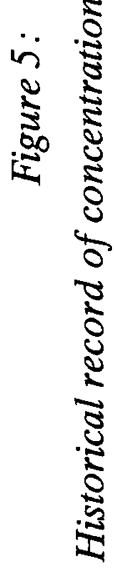

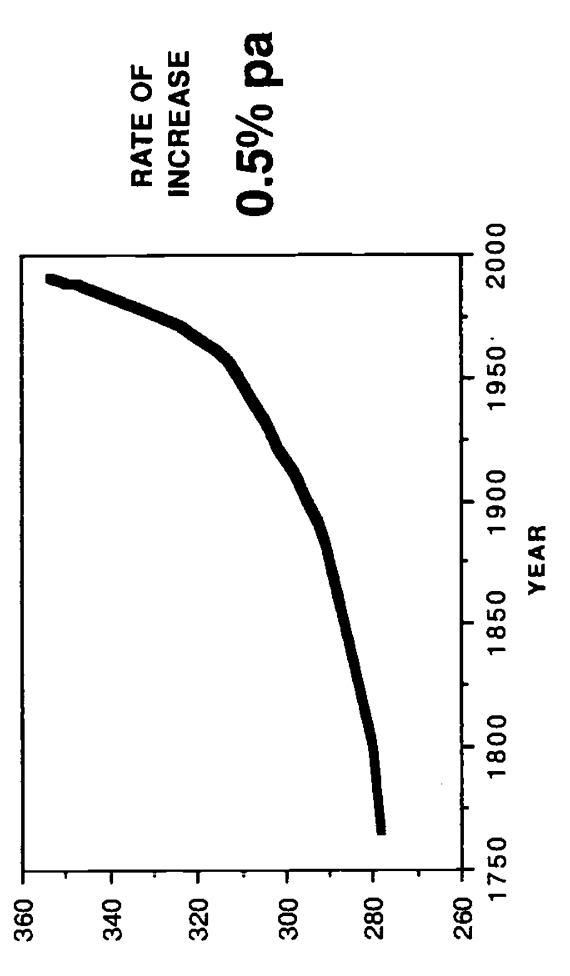

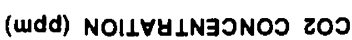

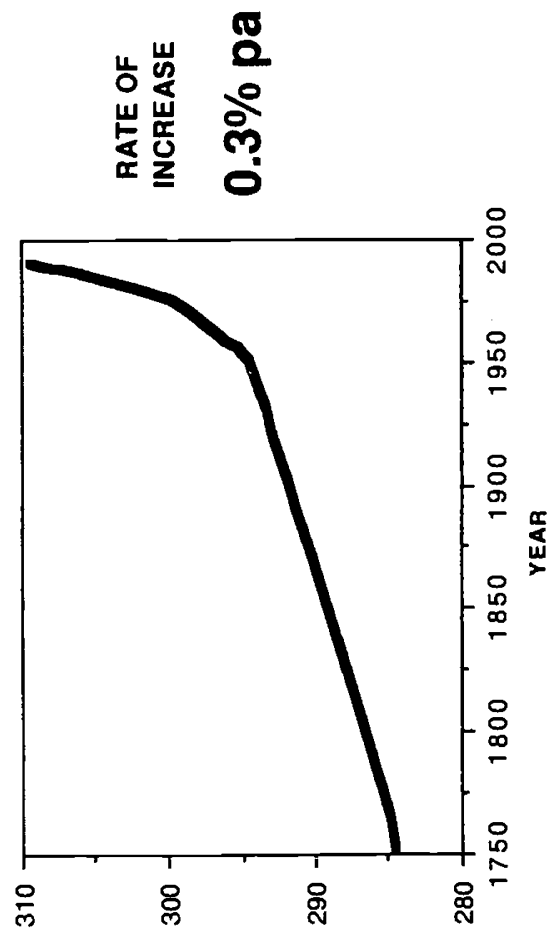

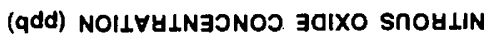


The next question is what is the historical record of these gases in the atmosphere? Figure 5 shows the concentration versus time for each of the above components for the last 100 years or so. The vertical scale is the concentration of each gas by volume with the rate of increase at the present time noted on the right of each curve. Each component is different in terms of its effectiveness as a greenhouse gas - its contribution to the overall climate forcing is given in Figure 4.

The other historical time series of interest of course is the global mean surface temperature. Figure 6 illustrates the best estimate available from the historical record. It melds data from the ocean surface as well as our land. The scale is the deviation from the 1951-1980 average and shows about a $0.5^{\circ} \mathrm{C}$ rise since the early $1990 \mathrm{~s}$ - a reflection of the industrial age. It is important to note that there are quite wide "natural" fluctuations in the record and some controversy surrounds the exact assumptions used in processing the data. The smoothed curve, however, is generally accepted as the average record. I remind you of my nervous affection for the "average condition".

\section{Figure 6:}

Annual deviation of global mean combined land-air and sea-surface temperatures for the period 1861-1989 (shown by bars), relative to the average for 1951-1980.

The curve shows the results of a smoothing filter applied to the annual values.

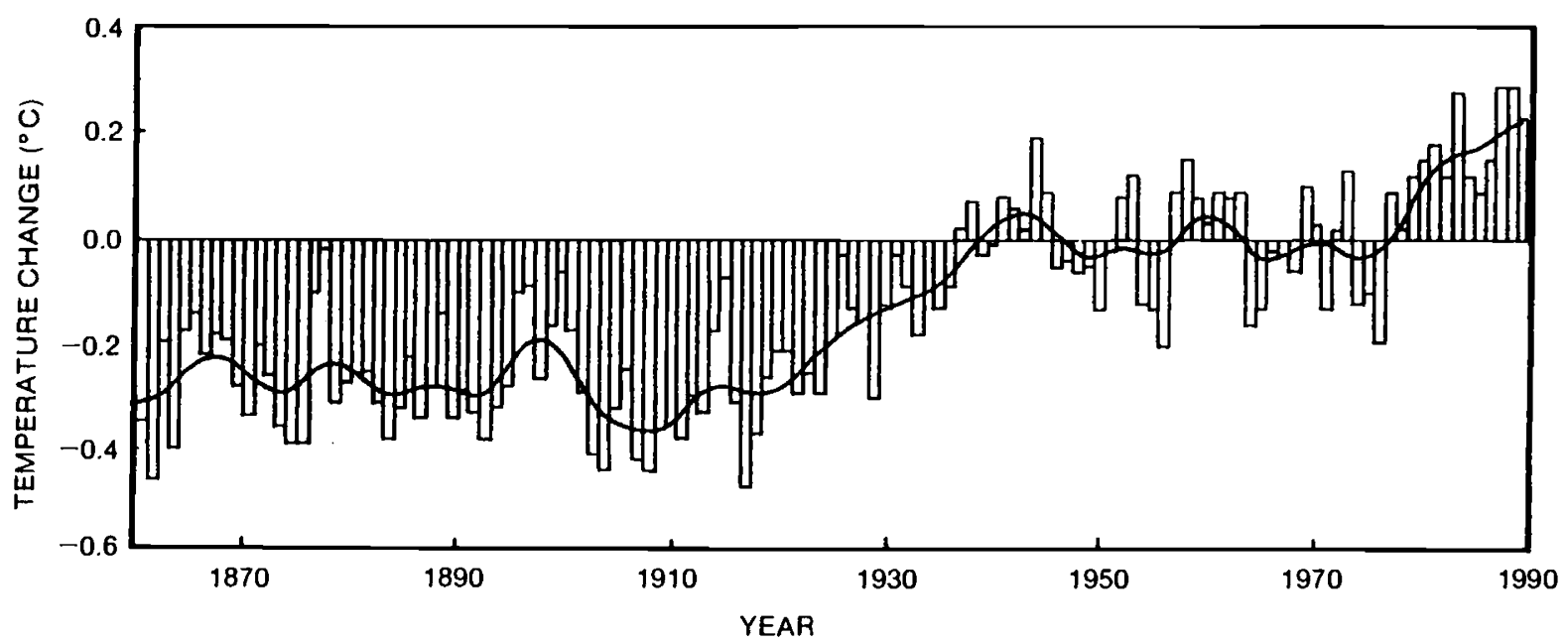

(Source: IPCC Report, 1990)

\section{Numerical simulation of the climate system}

So far, the discussion has been about average global conditions - a rather static look at something that in reality is a dynamic/interacting system. To really understand what all of this chemical change and subsequent impact on the global radiation and thermal budget means as far as climate is concerned, one seeks ways to understand the effect of these changes upon the circulation of the atmosphere and oceans. To do this we must develop models of the physical climate system - and for this we turn to numerical general circulation models (GCM) that couple the atmosphere with the land surface and ocean. 
A GCM as depicted schematically in Figure 7 is essentially a physical-numerical system through which the equations of mass, energy and momentum for the atmosphere and ocean are integrated forward together in time and over the global domain, in a way that simulates the behaviour of the real atmosphere-ocean system.

At each time step in the computation, the equations which describe the temporal evolution of the physical and dynamical processes in the atmosphere and ocean are evaluated numerically at each of a large number of points in a three-dimensional grid covering the whole globe (Figure 8).

The GCM approach involves explicit hour-by-hour simulations of weather systems over model times of decades or longer. Such work requires very fast super computers and accurate and efficient techniques for solution of equations. Present GCMs applicable to climate studies run at simulated time steps of about 30 minutes with horizontal resolutions of $500 \mathrm{~km}$ and 10 atmospheric levels in the vertical.

The GCM can be used in many ways to study the climate. For example one can construct a model atmosphere with the present level of greenhouse gases - run the model to develop an average condition (climate) and compare this with the observed data (distribution of temperature, precipitation, cloudiness, etc.). Given adequate simulation of the present climate, then another run of the model with higher levels of greenhouse gases can be done and the results compared. Such experimentation leads to the global average picture shown in Figure 9. This diagram is the familiar one of average global temperature versus time (see Figure 6). Here the high and low estimates are the measure of the uncertainty in the models - especially the role of the oceans and the effect of clouds on the radiation balance. The greenhouse forcing for this analysis is based on present policies and agreements that exist for control of greenhouse gases. Here the models present a very smooth picture which in reality will have a lot of natural variability superimposed upon the smooth curves. The important point here is that the sustained rate of change is larger than anything we have experienced to date.

The temperature rise is reflected in sea-level rise resulting from the thermal expansion of the oceans and a contribution from melting glaciers. Figure 10 illustrates the results computed from the climate models and the high and low estimates reflect the uncertainty limits to date.

The models also provide the beginning insights into some regional climate changes. To date, five areas have been selected for further investigation (Figure 11). These regional analyses are more uncertain than the global averages because different models often produce different results but it is interesting to look at these results so that one gets an indication of how much variability is masked if one simply looks at global averages. Considerable research is presently being initiated around the world to try to reduce the uncertainties in these regional analyses and to expand the work to cover all regions of the globe.

The models, however, can also be used to begin to develop answers to questions like :

- How will climate extremes and extreme events change?

- Will storms increase in a warmer world?

- What about hurricanes, tropical cyclones and typhoons? 
Figure 7:

The essential components of a coupled atmosphere-ocean general circulation model

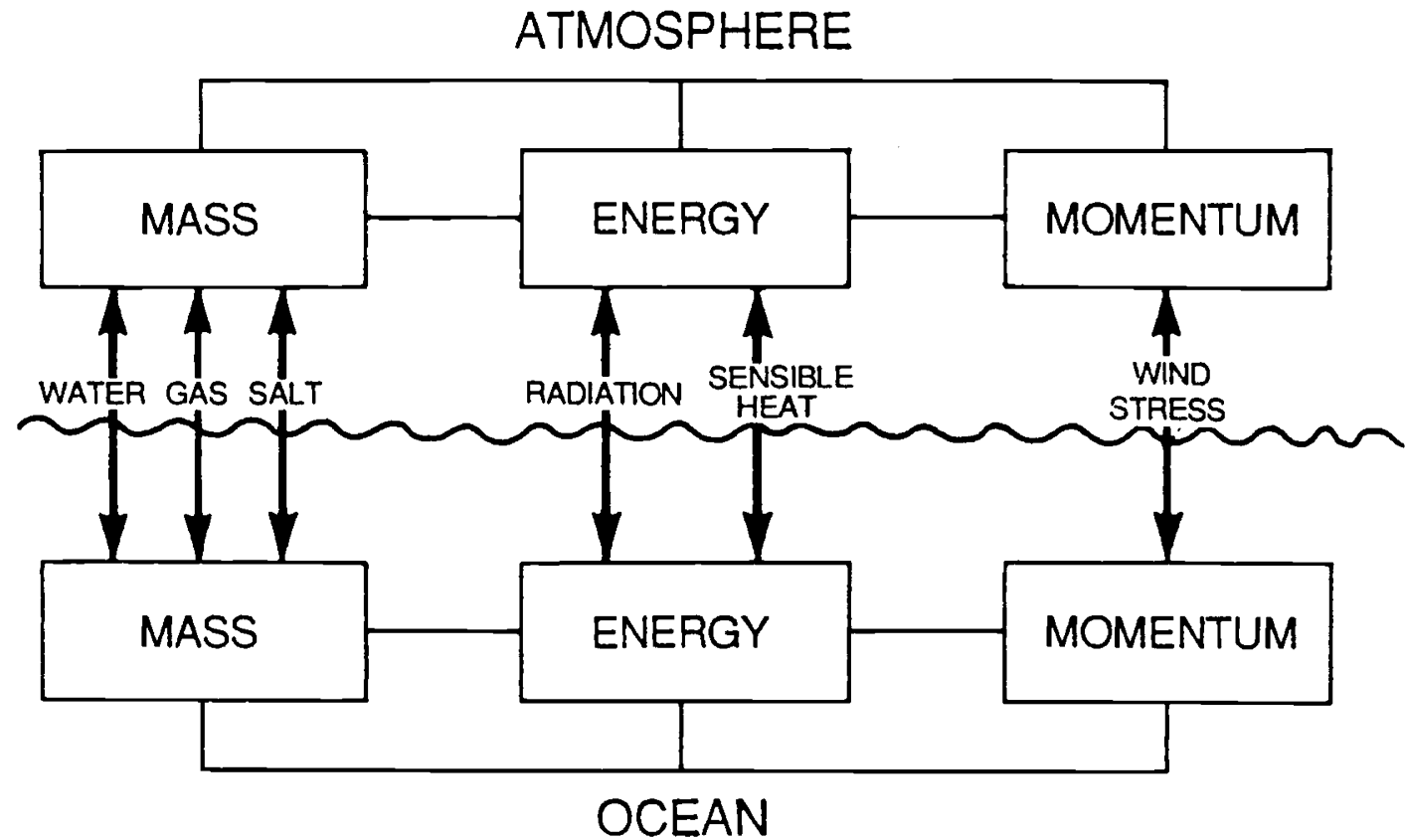

Figure 8:

A schematic view of the horizontal and vertical grid structure for a typical, fairly coarseresolution, general circulation model. The east-west vertical cross-section on the right (which corresponds to the boxed area of the grid on the left) indicates the terrain-following 'sigma levels' on which the numerical calculations are carried out.
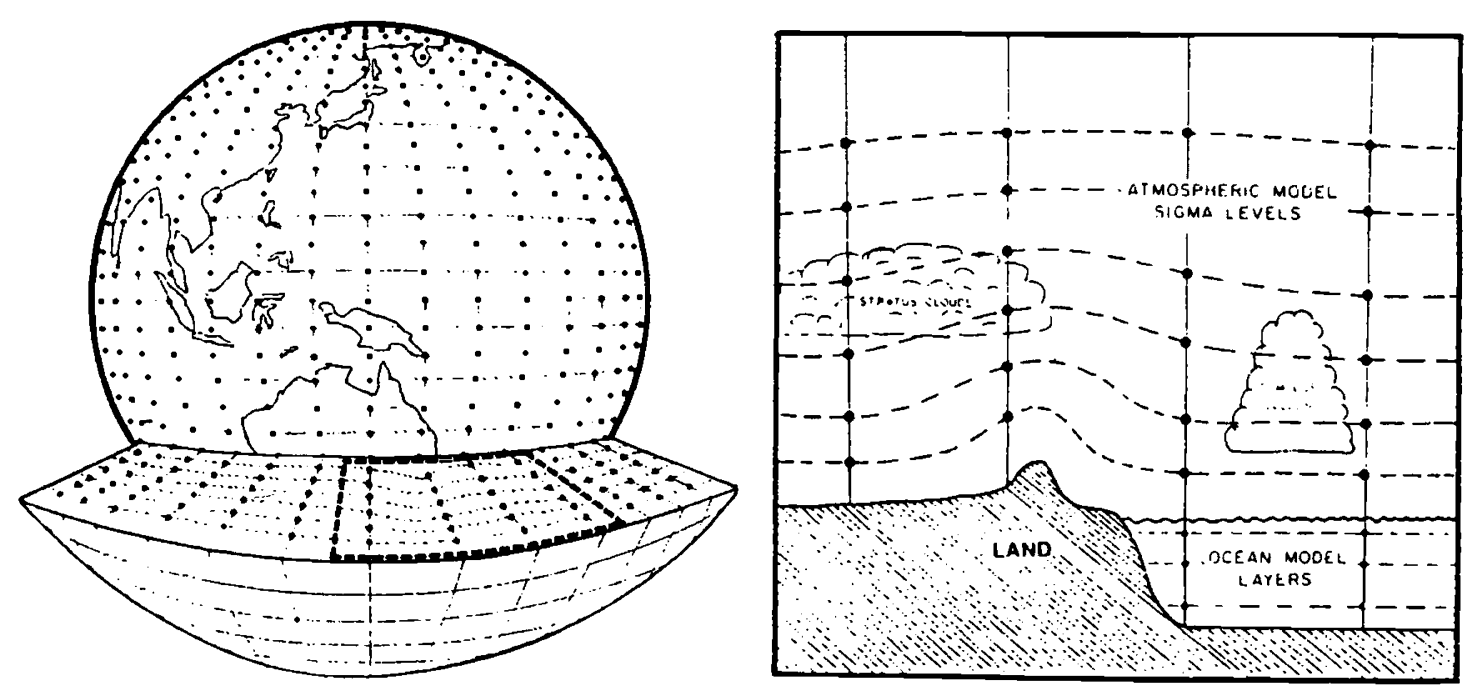

(Source: Zillman et al., 1989) 
Figure 9:

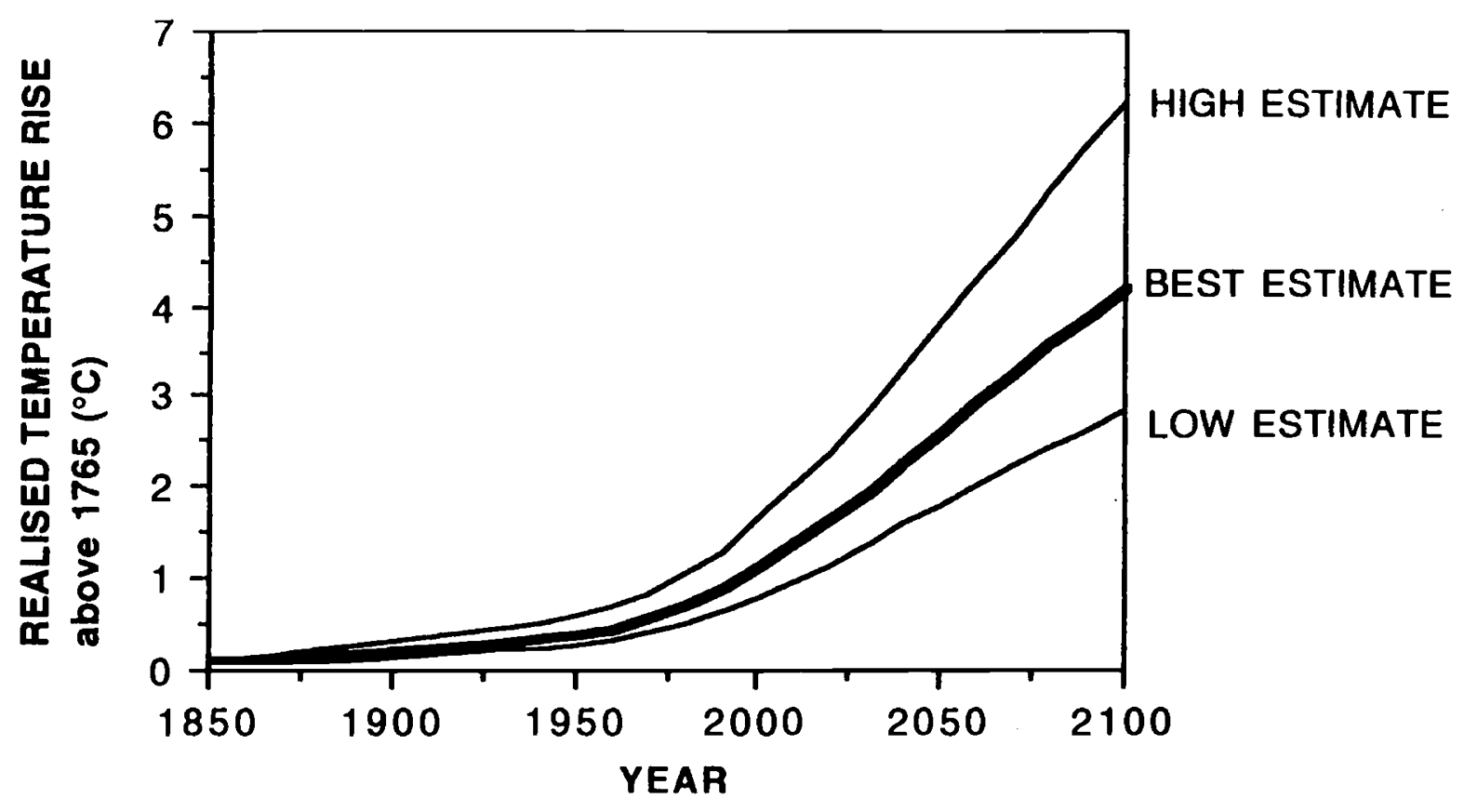

Figure 10:

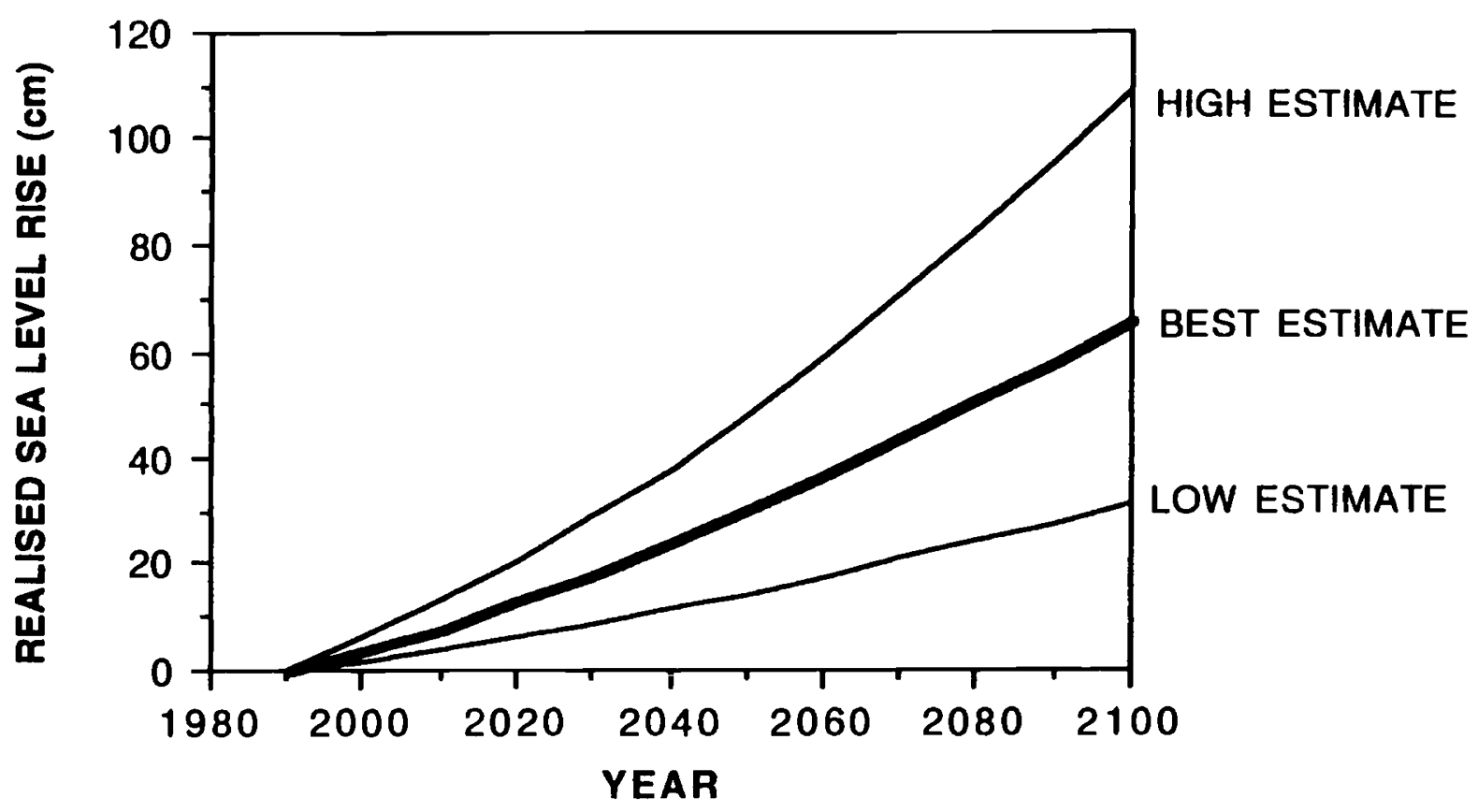

Source: Zillman, et al., 1989) 


\section{ESTIMATES FOR CHANGES BY 2030}

(IPCC Business-as-Usual scenario; changes from pre-industrial)

The numbers given below are based on high-resolution models, scaled to be consistent with our best estimate of global mean warming of $1.8^{\circ} \mathrm{C}$ by 2030 . For values consistent with other estimates of global temperature rise, the numbers below should be reduced by $30 \%$ for the low estimate or increased by $50 \%$ for the high estimate. Precipitation estimates are also scaled in a similar way.

\section{Confidence in these regional estimates is low}

\section{Central North America $\left(35^{\circ}-50^{\circ} \mathrm{N} 8^{\circ}-105^{\circ} \mathrm{W}\right)$}

The warming varies from 2 to $4^{\circ} \mathrm{C}$ in winter and 2 to $3^{\circ} \mathrm{C}$ in summer. Precipitation increases range from 0 to $15 \%$ in winter whereas there are decreases of 5 to $10 \%$ in summer. Soil moisture decreases in summer by 15 to $20 \%$.

Southern Asia $\left(5^{\circ}-30^{\circ} \mathrm{N} 70^{\circ}-105^{\circ} \mathrm{E}\right)$

The warming varies from 1 to $2^{\circ} \mathrm{C}$ throughout the year. Precipitation changes little in winter and generally increases throughout the region by 5 to $15 \%$ in summer. Summer soil moisture increases by 5 to $10 \%$.

\section{Sahel $\left(10^{\circ}-20^{\circ} \mathrm{N} 20^{\circ} \mathrm{W}-40^{\circ} \mathrm{E}\right)$}

The warming ranges from 1 to $3^{\circ} \mathrm{C}$. Area mean precipitation increases and area mean soil moisture decreases marginally in summer. However, throughout the region, there are areas of both increase and decrease in both parameters throughout the region.

\section{Southern Europe $\left(35^{\circ}-50^{\circ} \mathrm{N} 10^{\circ}-45^{\circ} \mathrm{E}\right)$}

The warming is about $2^{\circ} \mathrm{C}$ in winter and varies from 2 to $3^{\circ} \mathrm{C}$ in summer. There is some indication of increased precipitation in winter, but summer precipitation decreases by 5 to $15 \%$, and summer soil moisture by 15 to $25 \%$.

\section{Australia $\left(1^{\circ}-45^{\circ} \mathrm{S} 110^{\circ}-155^{\circ} \mathrm{E}\right)$}

The warming ranges from 1 to $2^{\circ} \mathrm{C}$ in summer and is about $2^{\circ} \mathrm{C}$ in winter. Summer precipitation increases by around $10 \%$, but the models do not produce consistent estimates of the changes in soil moisture. The area averages hide large variations at the sub-continental level.

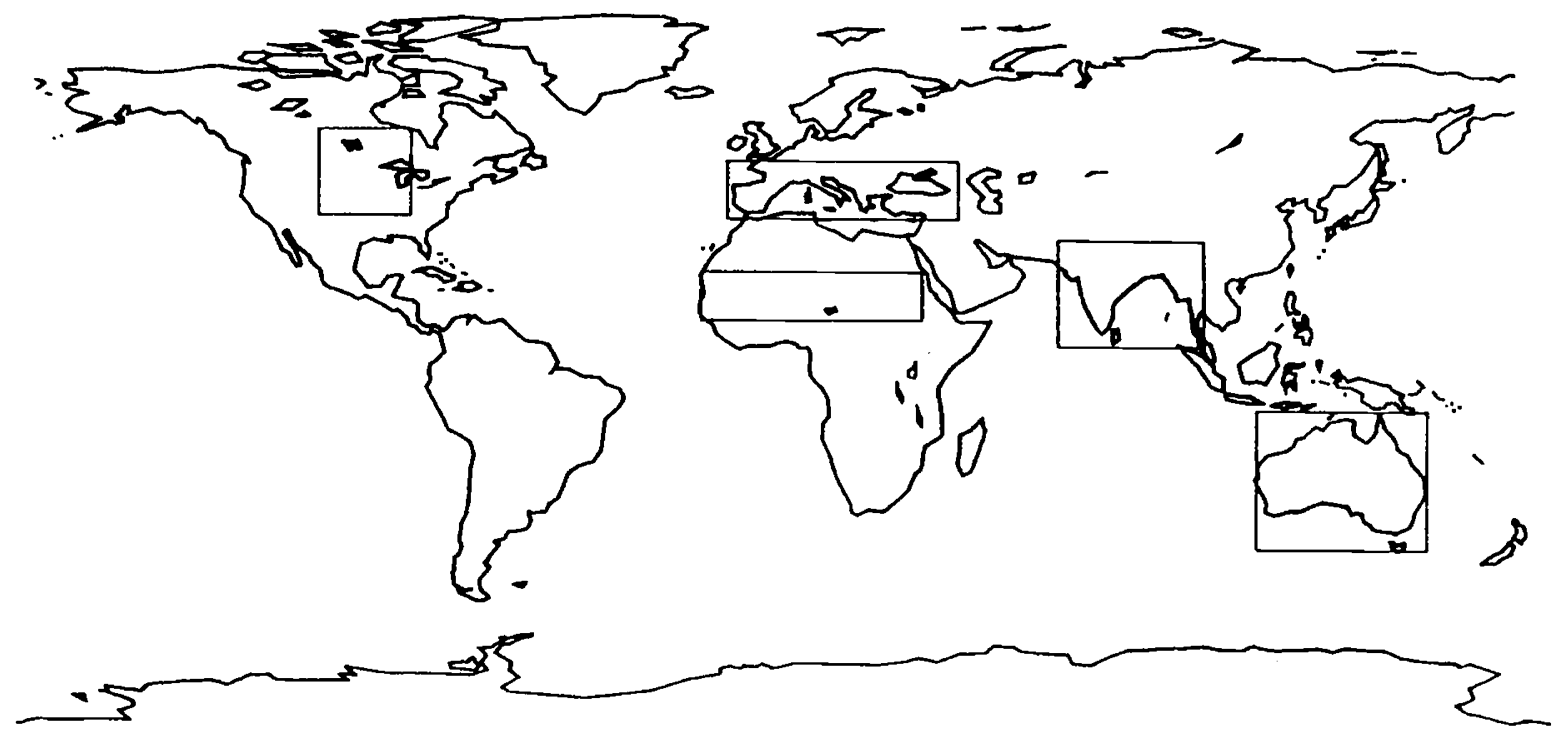

Map showing the locations and extents of the five areas selected by IPCC

(Source: IPCC Report, 1990) 
Large uncertainties exist in our knowledge so answers to these questions can be only general statements with strong caveats. Models need to be developed that simulate all parts of the climate system (recall Figure 1) before really solid answers can be given. Figure 12 illustrates the expected impact on extreme temperature, storm tracks, hurricane frequency, and other severe weather, based on present knowledge.

Figure 12:

\begin{tabular}{|l|l|}
\hline PHENOMENA & $\begin{array}{l}\text { IMPACT OF WARMING CLIMATE; } \\
\text { MODEL RESULTS }\end{array}$ \\
\hline $\begin{array}{l}\text { FREQUENCY OF } \\
\text { EXTPERATURE }\end{array}$ & $\begin{array}{l}\text { NUMBER OF DAYS PER YEAR BEYOND } \\
\text { A SPECIFIC THRESHOLD ON HIGH END } \\
\text { OF DISTRIBUTION WILL INCREASE. } \\
\text { LONGER HOT, DRY PERIODS }\end{array}$ \\
\hline $\begin{array}{l}\text { EXTRA TROPICAL } \\
\text { CYCLONE TRACKS }\end{array}$ & $\begin{array}{l}\text { SOME EVIDENCE OF LESS VARIABILITY } \\
\text { - MORE PREDICTABLE TRACKS }\end{array}$ \\
\hline $\begin{array}{l}\text { TROPICAL } \\
\text { CYCLONES }\end{array}$ & $\begin{array}{l}\text { POTENTIAL AREA FOR OCCURRENCE } \\
\text { INCREASED (SEA WARMER THAN 26 C). } \\
\text { NO EVIDENCE OF INCREASE IN } \\
\text { FREQUENCY OR STRENGTH }\end{array}$ \\
\hline $\begin{array}{l}\text { SEVERE WEATHER } \\
\text { (TORNADOES, HAIL, ETC.) }\end{array}$ & \begin{tabular}{l} 
PRESENT MODELS UNABLE TO RESOLVE \\
\hline
\end{tabular} \\
\hline
\end{tabular}

There is great anticipation that as computer capability gets bigger and faster and our observation resources become more comprehensive globally, especially over the oceans, our model results will improve in simulating the weather systems on a statistical basis.

Finally before drawing my conclusions, I would like to provide another frame of reference. Modern technology has allowed us to start seeing dimly into the future - it has also allowed us to look at our past.

The ice-masses on Antarctica and Greenland contain an invaluable record inbedded in the layer of ice accumulated annually over tens of thousands of years. By taking a deep ice core in a glacier in Antarctica one can determine the $\mathrm{CO}_{2}$ concentration from the air trapped in bubbles in the ice, and the temperature from the deuterium concentration (Figure 13). Here the scale is transformed to be time before present; what we see is a widely fluctuating natural environment with the global changes we have talked about being a small perturbation compared, for example, with the recovery from the last ice age. However, what we are concerned about is the rate of change - the present change is potentially faster than anything we see on this chart. 
Figure 13:

$\mathrm{CO}_{2}$ concentrations (bottom) and estimated temperature changes (top) during the past 160,000 years, as determined on the ice core from Vostok, Antarctica (Barnola et al., 1987)

Temperature changes were estimated based on the measured deuterium concentrations

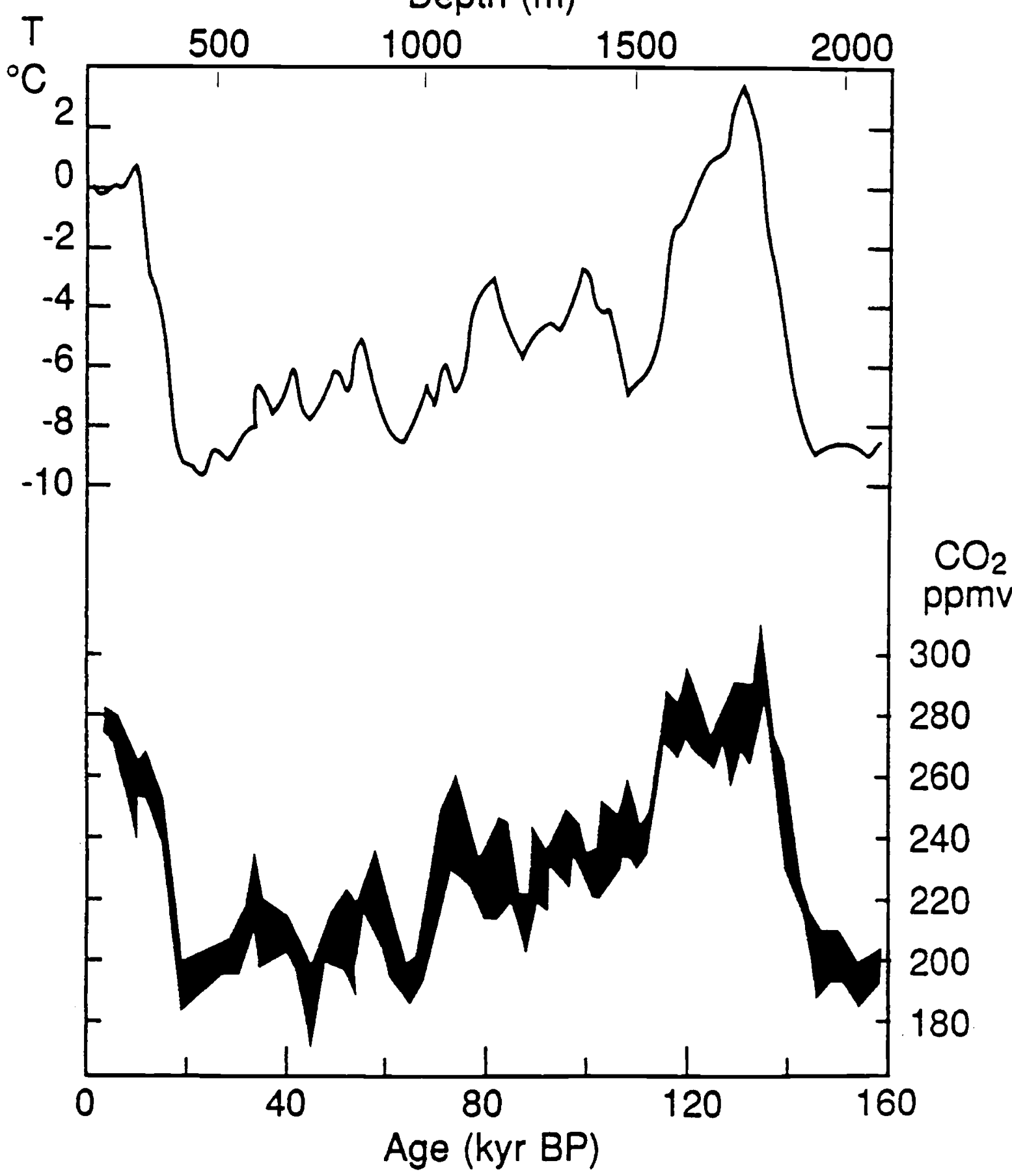

(Source: IPCC Report, 1990) 


\section{Conclusion}

In conclusion I would like to leave you with the following summary (see more detail in reference 1):

We are certain that:

- There is a natural greenhouse effect which already keeps the Earth warmer than it would otherwise be;

- Emission of greenhouse gases from human activities are substantially increasing and this will result in additional warming.

We calculate with confidence that:

- The radiative effects of the gases (some more efficient than others) and their effectiveness as greenhouse gases can be estimated;

- Atmospheric concentrations of long-lived species adjust only slowly to changes in emissions. It will take a long time (decades) to stabilize the concentration after emissions are controlled.

Based on model results, we predict:

- Global mean temperature rise of $1^{\circ} \mathrm{C}$ by 2025 and $3^{\circ} \mathrm{C}$ by end of next century;

- Controls on emissions can impact this change;

- Land surfaces warm more than oceans and high northern latitudes warm more than the global mean in winter;

- Regional climate change will often be much different than the global mean;

- Global mean sea-level is predicted to rise $20 \mathrm{~cm}$ by 2030 and $65 \mathrm{~cm}$ by end of the next century, unless emissions are controlled.

There are many uncertainties - e.g. understanding of:

- The sources and sinks of greenhouse gases;

- The effect of clouds which strongly influence the magnitude of climate change;

- The oceans which affect the timing and patterns of climate change;

- The polar ice sheets - affect on sea-level rise.

Research and observations are needed to address these uncertainties.

Presently there is a major debate going on regarding what governments can and should do in the likely event that this (or similar) climate change takes place. One view is that the world should try to be much more energy efficient and rely on adaptation by society to handle the problem - the other is to take a much more activist's role and legislate to reduce the emission of greenhouse gases, to organize a "law of the air" to enforce the global interest. As one might expect there are vast differences in opinion among nations on these issues. Developing countries, for example, see this very differently than the developed, industrialized nations do. The forum for this debate is the United Nations which is working to develop a framework for an International Climate Convention. 
The results of these activities will have a long lasting and significant impact on the lives of our children and their children. My view is much less alarmist than some but I certainly have the view that we cannot be complacent about the issue. We must become conservationists in our energy use; we must be more concerned and intelligent about our waste management; we must adjust our policies and practices to be better environmental members of the global community. Through these commitments we will reduce the rate of change and give the natural environment a chance to adapt to the changes. The chances for an uncontrolled environmental change because of the "greenhouse effect" are not insignificant. 